\title{
A CONTRIBUTION TO THE STUDY OF MASTITIS IN COWS.
}

\author{
By JAMES Henderson, M.R.C.V.S., Edinburgh.
} (From the Laboratory of the Royal College of Physicians, Edinburgh).

THE diseases common to the udders of cows have, for some unexplained reason, been rather neglected by the standard writers on veterinary science in this country, and, considering their importance in relation to the milk supply, this neglect is rather unaccountable. There is, however, a great deal of literature recording the researches of men of the veterinary profession on the continent of Europe. Their names include those of Nocard, Bang, Kitt, Jensen, Zschokke, Leblanc, Guillebeau, and others. Leblanc in I9OI issued a small book on the diseases of the udders of domesticated animals, which summarises the work of others and is an excellent exposition of the subject.

The purpose of the following investigation is to describe some of the inflammations of the udders of cows which are most commonly met with in veterinary practice. A series of cases of mastitis is described just as they emerged in the course of slaughter-house inspection, and without selection, except in so far that only cases in which an immediate bacteriological examination was possible were taken, i.e., from two to eight hours after death.

The methods followed were: (I) to note the external appearances, and what may be disclosed by palpation; (2) to describe the macroscopic appearances of the tissues on section ; (3) to record the result obtained from examining cover-glass films direct from the tissues ; (4) to describe the microscopic appearances of sections of the tissues; and (5) to give the result obtained by cultures taken from the tissues.

After examining fourteer cases of mastitis it was found necessary to examine the normal udder for purposes of comparison. In each mastitis species of bacteria constantly recurred which had no pathogenic effect on laboratory animals. This suggested the possibility of their constant occurrence in the normal udder. Seven normal udders were examined, and for convenience these will be considered before the diseased ones.

\section{NORMAL UDDERS.}

CASE I.-Two quarters on one side were removed from the carcase of a cow for examination. The animal had been disused as a milker for about three months. The skin was thoroughly asepticised by means of lysol, alcohol, and æether, and a transverse section was made with a hot knife about 4 inches above the base of the teat and superior to the sinus. Four cultures were made and several coverglass films. The films did not give very satisfactory evidence of the presence of bacteria.

Bacteriology.-The cultures, however, all showed the presence of bacteria. The first twenty-four hours' incubation at $37^{\circ}$ developed only a few minute colonies on the two blood-serum tubes, but they grew well at room temperature. Two kinds of micro-organisms were isolated, a staphylococcus and a bacillus. 
The staphylococcus colonies were greyish-white and slimy. This coccus has been repeatedly isolated, and in its growth on ordinary media it very closely resembles the staphylococcus pyogenes albus, but the cocci are larger, sometimes vacuolated, and sometimes they exhibit one deeply staining granule, and yet again both these features may be absent. This micro-organism is very commonly found in both normal and diseased udders.

The bacillus, when studied, appeared to be identical with the bacillus subtilis, except that it liquefied blood serum much more rapidly than did a culture of that bacillus obtained from a hay infusion.

Although the occurrence of bacteria in the normal udder was suspected, the actual finding of them came somewhat as a surprise. I Iras not then aware that they had been found by various Continental investigators. In order to verify the results of the second and all subsequent examinations of normal udders, cultures and films direct from the tissues were made by independent observers, for which my thanks are due to Dr W. T. Ritchie and Mr Watson.

CASE II.-In this case two quarters of one side were examined. (This procedure obtained throughout the series.) They were taken from the carcase of a cow which had been milking probably no less than eight months.

Experiment.-A guinea-pig was injected intraperitoneally with $2 \mathrm{cc}$. of the fluids exuding from an incision into one quarter. No result.

Films direct from the udder yielded no definite result.

Bacteriology. $\perp$ Twenty cultures on various media were made from the tissues. Nine of these were made by $\mathrm{Mr}$ Watson, the assistant having charge of the bacteriological work of the laboratory, and the rest by myself. With the exception of five, all showed the presence of micro-organisms.

The colonies which largely predominated were those of staphylococci. A few of these were pale yellow, the rest greyish-white, profuse, and slimy. Next in frequency of occurrence came a fairly large sporulating bacillus. It is decolourised by Gram's method, but only feebly retains the stain. It is feebly motile. It has a marked enlargement in the centre indicating the growing spore. On agar streak culture, after twenty-four hours at $37^{\circ}$, it exhibits a profuse but delicate transparent growth. Magnified 50 diameters the colonies are raised, light brown, and non-granular. Gelatine is not liquefied. On blood-serum the medium is energetically liquefied, and when the process is complete there remains a grey stratum above the liquid. Milk is not coagulated, and its reacticn remains neutral to litmus, alkaline to cochineal. Peptone is present. Old milk cultures are whey-like, with a thick white pellicle. This bacillus belongs to the genus tyrothrix, as described by Duclaux. ${ }^{1}$

CASE III.-The two quarters were taken from the carcase of a cow in full milk, which was slaughtered on account of leg fracture. Nine cultures were made from them-three by $\mathrm{Dr}$ Ritchie, four by $\mathrm{Mr}$ Watson, two by myself.

Bacteriology.-The three cultures made by Dr Ritchie were on the surface of agar. Two were made from a tissue section far from the sinus, and the third was taken from the fluids of a duct near the sinus. All three exhibited a very scanty growth of a pseudo-diphtheria . 1 Sce "Bacteriology of Milk." Swithinbank \& Newman, 1903. Pp. 447-451. 
bacillus in pure culture. After forty-eight hours' incubation of bouillon sub-cultures at $37^{\circ}$, the reaction was still alkaline, and staining by Neisser's method exhibited no polar granules.

Of $\mathrm{Mr}$ Watson's cultures one agar and one bouillon were made from sections of the tissue near the sinus, and other two of like media were taken from a duct at the sinus.

The agar tube made from the gland tissue section was sterile. The bouillon from the same locality was slightly turbid after twenty-four hours at $37^{\circ}$, and films from it exhibited two different bacilli. One of these was short and motile, frequently formed chains and filaments, and was decolourised by Gram. The other was the pseudo-diphtheria bacillus. The agar culture taken from the duct exhibited profuse white colonies of staphylococci. The bouillon culture from the duct exhibited the staphylococci and the pseudo-diphtheria bacillus.

The two agar cultures made by myself from a tissue section in the upper third of one quarter were both sterile.

CASE IV.- In this case two quarters on one side were obtained from a neighbouring abattoir. There was no history of the cow to which they belonged, but they were apparently quite normal as regards size, palpation, and appearance on section.

Films made directly from section of the gland tissue and from ducts at the sinus exhibited only a very few isolated micro-organisms.

Bacteriology.-Six cultures from this udder were made by a fellowworker and examined by me.

(I) Bouillon.-Loop scraping from the surface of the udder tissue on section. Sterile.

(2) Bouillon.-Loop scraping from a deep duct. Sterile.

(3) Bouillon.-Loop scraping from a deep section into udder. It exhibited a pure culture of the pseudo-diphtheria bacillus.

(4) Blood-serum.-Loop scraping from a section into udder. Exhibited one colony of a diplococcus.

(5) Agar.-Loop scraping from a section into udder. Exhibited one large white colony of staphylococci.

(6) Bouillon.-Loopful of milk from one of the main ducts. Exhibited four different micro-organisms. The most abundant form was the bacillus of pseudo-diphtheria, next a large bacillus resembling bacillus subtilis, then streptococci, and last a small short bacillus. This last mentioned bacillus when isolated and studied was found to be identical in its cultural features with the bacillus murisepticus of Flugge and Koch, with this important exception that it was not pathogenic to mice.

Experiments.-(I) A brown mouse was injected intraperitoneally with 5 cc. of a bouillon culture, which had been incubated for twentyfour hours at $37^{\circ}$. No result.

(2) A tan mouse was similarly injected with $\cdot 5 \mathrm{cc}$. of a bouillon culture incubated for forty-eight hours at $37^{\circ}$. No result.

Four cultures were made by $\mathrm{Mr}$ Watson.

(I) Bouillon, from section into the gland tissue, remained sterile.

(2) Agar slope, from the same, exhibited one large white colony of staphylococci.

(3) Bouillon, from a duct near the sinus, exhibited streptococci in long chains and the bacillus of pseudo-diphtheria.

(4) Blood-serum, also from a duct, exhibited (I) a few of the small dry 
grey colonies of pseudo-diphtheria, (2) one or two whitish colonies of staphylococci, each coccus exhibiting one deeply staining granule, and (3) one yellowish colony of a large bacillus. The latter bacillus in a day or two began to discolour and liquefy the medium.

CASE V.-As in the last case, two quarters of one side were obtained from a neighbouring abattoir. There was no history of the cow except that it was a dry cow brought there to be slaughtered and dressed as beef for the market. The quarters appeared to be normal in flaccidity and on section.

Nine films were made from one quarter, all from the milk sinus walls and the large ducts opening into the sinus, excepting one, which was made from a deep duct. Contrary to the usual experience, three of these films exhibited unmistakable chains of streptococci. That from the deep duct exhibited at least four chains, and the others one or two each.

Experiment. - A guinea-pig was intraperitoneally injected with $2 \mathrm{cc}$. of the fluids taken directly from a section into one quarter. No result.

Bacteriology.-Dr. Ritchie made two cultures on serum agar. One from a section of the gland tissue showed a few colonies of streptococci, the other from a duct exhibited streptococci, staphylococcus albus, and a bacillus resembling the pseudo-diphtheria bacilius, but which differed from those pseudo-diphtheria bacilli already found in that it exhibited polar granules when stained by Neisser's method.

Experiment. - A guinea-pig was subcutaneously injected over the lumbar region with $2 \mathrm{cc}$. of a bouillon culture of this pseudodiphtheria bacillus incubated for twenty-four hours at $37^{\circ}$. No result.

Mr. Watson made four cultures. Two were made with loop scrapings from ducts and two from gland tissue, all from sections above but near to the sinus. Two were sterile and two exhibited streptococci.

My own cultures were five in number-four from loop scrapings of large ducts leading into the milk sinus, and one from a duct in that neighbourhood exposed by section. The four from the sinus ducts exhibited streptococci only, except that one also exhibited a whitish colony of the large staphylococcus. The fifth culture from the deep duct exhibited two colonies of a micro-organism not previously met with. This is a sporulating bacillus with an oval spore at one end like a drum stick. Its length is from three to eight times its width. It is feebly motile, the longer forms have undulating motion; in some of the shorter it is rotatory. It stains by Gram's method, and is not acid-fast, but after staining in hot carbol-fuchsin it is not decolourised by thirty seconds treatment with absolute alcohol. Colonies in gelatine Esmarch tubes after forty-eight hours' incubation at room temperature are not visible to the naked eye, but magnified 50 diameters the surface colonies appear droplike, circular, and delicately granular. The deep ones are round and dark brown to black in colour. In three days liquefaction is apparent, when the deep colonies magnified 50 diameters present a seething mass of coarse granules in motion. In agar plates there is no appearance of growth to the naked eye in twenty-four hours at $37^{\circ}$, but after forty-eight hours at $37^{\circ}$ small bluish colonies appear. Magnified 50 diameters the surface colonies are rounded, with one or two short blunt processes projecting 
at the edge, and are delicately granular and homogenous; the deep colonies are very dark and root-like, with short blunt processes projecting. Milk is not coagulated. In bouillon turbidity is not very marked. In fluid media the bacilli are frequently in pairs, often forming an obtuse angle. In old cultures of blood-serum there is partial liquefaction, the liquid having the appearance of water. It grows well at room temperature, and rather better anærobically than xrobically.

CASE VI.-In order to discover the period at which bacteria gained access to the udder, two quarters on one side were removed from the carcase of a heifer and examined. They were quite unexpanded. The animal was of the polled Angus breed and had only the two central permanent incisors erupted, and therefore was probably a little under two years old.

Mr Watson made four cultures from the gland tissue and the ducts exposed by the section.

I made six cultures from the sinus and ducts opening into it. All were sterile.

CASE VII.-Another heifer's udder was examined in the same way. The carcase from which the two quarters were taken was that of a shorthorn heifer with four permanent incisors erupted, or about two and a half years old. She carried a foetus of about two months old. The udder was slightly expanded, and the sinus contained a clear thickish fluid

Eleven cultures were made, and all remained sterile.

\section{General Considerations.}

Most writers on this subject state that milk taken from the normal udder under aseptic conditions is sterile, and conclude therefrom that the interior of the gland is sterile. But this may only mean that the micro-organisms are associated with the walls of the ducts, and may not be withdrawn with the milk. As this is a matter of vital importance I will quote at some length from two recent writers on this subject. The following is translated from Leblanc's work already referred to. ${ }^{1}$

"M. Nocard has first established that the teat canal could serve as an avenue of entrance for pathogenic germs. This fact threw a vivid light on the pathology of mastitis. It established that the infecting agent has no need to penetrate the udder by abrasion of the skin, but that it has at its disposal a way of entrance always open and at hand, viz., the teat canal. This represents a capillary tube constantly moistened by milk, and consequently in excellent condition to serve as a means of conveyance for the micro-organisms which thus find 'a culture medium, and a road already made to reach the sinus' (Kitt).

"It thus becomes easy to understand the evolution of mastitis. The infected sinus represents the vestibule of the milk ducts in the same way as the pharynx represents the entrance to the respiratory and digestive systems. Just as bronchitis frequently succeeds pharyngitis, so mastitis often follows infection of the milk sinus.

\footnotetext{
1 "Les Maladies des Mamelles chez les Animaux Domestiques," par P. Leblanc, 1901, p. 72.
} 
Urethritis is a constant menace of orchitis and of cystitis, and the infection of the milk canal may have for the udder consequences as serious.

"It is no longer necessary to believe that the milk sinus of an udder which acts normally is exempt from germs. Most authors who have written upon bacteriology say that to obtain milk free from germs it is sufficient to draw it aseptically from the udder. That is absolutely an error.

"Of sixteen healthy cows examined under thoroughly aseptic conditions Guillebeau observed nine times infection of the teat canal. Zschokke has written that the sinus and the canal are constantly infected, like the mouth for example. This is certainly a manifest exaggeration, and the truth lies between the two. Six times out of ten we have found the milk sinus infected in the case both of the cow and the goat. Aseptic conditions were secured by means of superficial cauterisation, the udder being removed.

"In the majority of cases the habitual inhabitants of the sinus were found to be diverse varieties of staphylococci-S. albus, S. aureus, S. citreus. The variety which predominates is the aureus, but the three varieties can be found side by side.

"We do not attach any considerable importance to the presence of these germs in the vestibule of the milk ducts, because their pathogenic action has never been established. There is, however, room to think that if they are not the agents of mastitis they contribute to increase the gravity of the malady, and, perhaps, to cause the formation of mammary abscesses.

"Normally, then, the milk sinus is frequently inhabited by a considerable number of microbic colonies."

Otto Uhlmann," a still later investigator, writes: "Until recently it was generally accepted that the secretion of the milk gland was free from bacteria, unless an ascending invasion through the teat canal caused a continuous infection of the secretion and gland itself with bacteria. That the milk is practically never germ free has been established by different investigators.

"The rationale of this has been given by bacteriologists who, like von Freudenreich, made use of fresh sterile milk in their researches, and who spared no pains to get if possible such milk. The natural sterility of milk, the work of Barthels, Ward, von Freudenreich, Burri, Boekhout and Ott de Fries, Backhaus and in more recent times Lux, is now definitely not to be regarded as a condition which is ever really present.

"With the establishment of this fact, however, comes the question by what avenue the bacteria gain access to the gland. It is selfevident that two possible avenues present themselves-the blood stream, and the teat canal, or both.

"It is the task of research to investigate the significance of these possibilities.

"I will now endeavour to state exactly what is the condition of the teat canal with regard to its bacterial flora, because the theory of invasion through the ductus papillaris has been up to the present time in favour. It has already been formulated as being acceptable in

\footnotetext{
1 "Centralblatt fur Bakteriologie, Parasitenkunde, und Infektionskrankheiten," 30th Novem. ber 1903 , p. 224 .
} 
view of the causal requirements of the case. Kitt ${ }^{1}$ compares the above canal to a capillary tube reaching from the exterior of the teat up to the milk cistern. This column of milk forms a convenient highway for bacteria advancing from the contaminated outside surface to the milk stored in the cistern."

Uhlmann found, by making serial sections of the teats of healthy cows, goats, and sheep, that the teat canal is inhabited by many microorganisms, and records having found them in the amorphous plug which sealed the external opening of the teat canal in a one-year-old heifer.

It must be stated, however, that Kitt, in his work entitled " Bakterienkunde und Pathologische Mikroskopie" (I903), p. 389, says that "The normal milk inside the udder, and at the moment of milking, is absolutely free from micro-organisms." Further on, p. 395, he states that by simply rubbing a potato culture of the bacillus phlegmasiæ uberis upon the external opening of the teat, so that some of the culture remained there, he produced the characteristic mastitis in a cow. Here he repeats the statement that the teat canal is a capillary column in which there is always milk, and consequently bacteria can easily penetrate from the teat opening to the milk cistern. It would thus seem that other bacteria, whether pathogenic or not, can penetrate from the outside into the milk cistern by the same channel.

There is no doubt that the blood stream brings bacteria to the udder in some cases of tubercle and probably other diseases. But that the teat canal is the avenue of advent lin a vast preponderance of cases is, I think, indicated by the observations herein recorded.

It appears that, excepting those of central origin, the species of bacteria found in a particular udder depend upon the accidental presence of these species in its outside environment, and it is beyond doubt that in those which I have examined a more exhaustive examination would have revealed the presence of many more species than are here recorded. Further, it is found that the localities inside the udder which were richest in bactcria were the opening of the main milk ducts into the sinus and the sinus itself. As the examination receded into the deeper ducts, and still more markedly when the parenchyma in which no large ducts were visible, was examined, the colonies on the culture media became progressively fewer.

There is reason to believe that these adventitious germs are almost exclusively confined to the walls of the milk ducts, and that they exist there as epiphytes rather than as true parasites. The fact that they are so difficult to demonstrate in films taken directly from the ducts and parenchyma shows that, relatively speaking, they are few and isolated. This is also borne out by the fact that comparatively few colonies appear on tubes of solid media.

Some of the germs found in the normal udder might well be derived from the bedding-litter, the fodder, the fæces, and perhaps most importantly of all, the hand and person of the milker. From these sources also, in all probability, come the virulent micro-organisms which directly produce mastitis.

1 "Lehrbuch der Pathologischen Anatomie der Haustiere," 2nd aufl, bd. I., 1900, r. 201-207. 
II.-MASTITIS.

The following cases of mastitis are grouped into three classes, viz. :-

Tubercular, III. and V.

Purulent, VII. an'd VIII.

Parenchymatous, I., II., IV., VI., IX., X., XI., XII., XIII., and XIV.

The reasons for this classification will be stated after they have been described. The numbers given to them indicate the order in which they emerged.

\section{The Tubercular Type.}

CASE III.-This was taken from an Ayrshire cow about nine years old. The carcase exhibited generalised tuberculosis, and the disease had infiltrated the udder. The right half of it was markedly enlarged, particularly the posterior quarter. The skin covering these quarters was quite loose, and felt as if it intimately covered the indurated parenchyma, without the intervention of much subdermal areolar tissue. The indurated parenchyma felt stringy and ridged, but not nodular as might have been expected. This induration felt much more compact and hard than cases of mastitis of other origin. The most diagnostic tubercular feature was that the infiltration had accurately followed the original outlines of the quarter, so that the adjacent corners of the quarters on the lower surface could be distinctly felt where the transverse septum dividing the quarters, and the longitudinal septum dividing the two halves, approached each other. The ridge bounding the quarters along the longitudinal septum was also distinctly palpable. In ordinary mammitis the effusions and other inflammatory products practically obliterate these corners and ridges. Where the tuberculous induration becomes compact there is seldom any exudation between the skin and the indurated parenchyma. The non-nodular surface of the induration is not at all uncommon in tubercular mastitis. The compact induration did not extend quite to the base of the udder. The soft part had a firmer consistency than the normal tissue, but could not, if found apart from the compact induration, be diagnosed as tubercular. In a quarter or part of a quarter thus invaded, i.e., before the interstitial tissue has become markedly developed and compact, the milk production is not arrested, but stimulated, and bacilli are passed out with the milk.

A section was made of the hind quarter from the teat to the base. The lower two-thirds of the cut surface disclosed the thoroughly invaded area in a solid block. The subdermal areolar tissue was not invaded. In colour this solid induration was only of a slightly deeper yellow than the normal gland tissue. Each lobule of acini was distinctly outlined, giving the surface a mosaic appearance, each piece in the mosaic being about the size of a split grain of pearl barley. The dividing lines between the lobules, however, were very faintly marked, and the pieces bulged very slightly upon the cut surface.

Films from this compact area were exceedingly rich in tubercle bacilli.

The area of softer consistency did not differ from normal gland 
tissue in colour. Films made' from this area showed not nearly so many bacilli as those from the compact tissue. This is the primary stage of the invasion, and by gradual transformation it passes into the secondary stage, which is the compact induration. Where the whole quarter is composed of the hard compact tissue the lesion has attained considerable age, and it is only then that calcification sets in. This third stage begins as a rule in the neighbourhood of the teat and advances upwards. It can be discovered by the grating sound emitted on section. When calcification is present the interlobular connective tissue is markedly increased, and can be seen by the naked eye, clear, white, and tough. The parenchyma then shows the unmistakable yellow tuberculous character. This advanced condition is rather rare.

Histology.-Sections of the soft tuberculous tissue show a considerable increase in the interacinous connective tissue, with active cell proliferation. There is a great increase in leucocytes present, but the outstanding feature of this section is the extraordinary increase in the number of the secreting cells lining the acini. This recalls and substantiates an observation by the late Professor Walley, that at the outset tuberculosis of the udder increases the secretion of milk. Few tubercle bacilli were found in this section.

A section of the compact tissue exhibits a vast increase in the amount of interlobular, and still more of the interacinous, connective tissue. The acini are often compressed to a mere slit. The abnormally numerous secreting cells of the acini are seen to be compressed laterally or obliquely, giving them a palisade appearance. In these solid areas are seen caseating foci, often with giant cells in the neighbourhood. The tubercle bacilli are abundantly distributed throughout these areas; groups are seen inside the giant cells. The leucocytes and connective tissue cells are all markedly multinucleated.

Bacteriology.-Cultures were made from this mastitis, but the hopes of a pure culture of tubercle bacilli vanished when the micro-organisms incident to the normal udder appeared. These were the large staphylococcus with the cultural features of pyogenes albus, which was most common, and the bacilli of pseudo-diphtheria. The latter differed from those found in the normal udder, inasmuch as bouillon cultures gave a slightly acid reaction.

Experiment.-A guinea pig was injected intraperitoneally with I cc. of a forty-eight hours' culture of the pseudo-diphtheria. It died five months afterwards, apparently of a liver lesion, but I could not connect this with the above injection.

CASE V.-This was taken from a cow with generalised tuberculosis. The right half of the udder was enlarged and tubercular. The induration felt hard and compact, the skin was loose, and the surface of the induration felt ridged. Further description would simply be repetition of what has already been stated under Case III.

Cultures exhibited the white colonies of large staphylococci, and a bacillus resembling subtilis.

\section{The Purulent or Streptococcal Type.}

CASE VII.-This mastitis occurred in an old cow, the left half of the udder being affected. The two quarters were very greatly enlarged. The induration was in the lower part of these two 
quarters, and felt tumefied, hard, and stringy, while the upper part was soft and flaccid. The lower parts exhibited irregular, smooth, bulging areas. A considerable amount of skin in the neighbourhood of the teats felt very hard and adherent. Posterior to the hind teat were one or two openings, which had been discharging pus. At the time of this examination the pus was inspissated. This was a chronic lesion.

A section made from the teats upwards, cutting through the hard adherent skin, showed that the hardness and immobility of the latter were due to the fact that it was about 2 inches thick from the epidermis to the parenchyma. This tissue was very dense, white, and homogeneous, and in one place a pus sinus about twice the thickness of a pencil had burrowed through it to the outside, where it discharged pus. Between this dermal wall and the parenchyma an amber serous fluid was found. in the areolar tissue. Continuing the section upwards the milk cistern was found to be full of thick greyishyellow pus, having a fetid odour. The walls of the milk cistern were of thick, white fibrous tissue, and were lined internally by a thin friable blue-black film of necrotic tissue.

A transverse section through the lower third of the two quarters exposed three or four pus sinuses and numerous discrete small abscesses of varying size. The parenchyma above this purulent region did not appear to differ from the normal, except that it was rather more flaccid and voluminous.

Bacteriology. - Films of pus disclosed a perfect chaos of microorganisms among the degenerated cells and débris. The eye was at once arrested by chains of streptococci, which stained more deeply than the rest. Long badly-stained filaments were very noticeable. Occasional thick, deeply-stained bacilli appeared, and well-stained large micrococci occurring singly, or rather, hardly close enough to be described as forming groups. Closer examination disclosed myriads of badly-stained small cocci and bacilli.

Films from the tissue near the base of the udder exhibited only a large bacillus, sometimes in filaments, and a large coccus, often in pairs. No streptococci were found.

A film from the serum between the thickened skin and the parenchyma exhibited chains of streptococci.

Histology.-Two small pieces of tissue were taken, one from the inferior suppurating region containing a minute abscess, and one from near the base of the udder. In sections of the first piece there was a considerable increase of fibrous tissue, which compressed the acini in every direction, and crowded the secreting cells close together. These secreting cells were abnormally large and œedematous. Short chains of streptococci were occasionally seen in the interacinous tiscue, and groups of from four to six short bacilli. The latter were never observed inside the acini. The minute abscess exhibited chains of streptococci, up to about thirty members in a chain, and sometimes the terminal cocci were larger than the others.

Sections of the second piece, cut from the neighbourhood of the base of the udder, exhibited signs of commencing degeneration. The interacinous connective tissue seemed normal in amount, but the acini were rather larger than normal. The secreting cells were very odematous, their nuclei were hazily stained, and their outlines in- 
distinct or lost. The only micro-organisms observed were occasional large cocci occurring singly and a few large bacilli.

Bacteriology. - The two predominating micro-organisms exhibited in the cultures were streptococci, the colonies of which were greatly in the majority, and short bacilli of the colon type.

The streptococci exhibited short chains, the members of which were minute in size. Their growth on serum was in minute colourless colonies, and they possessed the exceptional power of slightly eroding the surface of the medium, so that they appeared sunk beneath the surface.

CASE VIII. - This mastitis resembles the last described very markedly. The fore and hind quarters of one side were affected and were greatly enlarged. The lower third of each quarter was indurated, and bulged out in places, which proved to be the sites of large abscesses. Between this abscess region and the base of the udder the parenchyma felt flaccid. The skin of the areas round the teats was adherent, hard, and thickened, and proved on section to be dense and white.

On section the parenchyma of the lower third which was not destroyed by suppuration,was greatly intersected by strands of white fibrous tissue, and the parenchyma often appeared as islands lying in a network of fibrous tissue. This was a chronic lesion of long standing.

Films made from the pus show myriads of micro-organisms, among which a small streptococcus is easily distinguishable as the prevailing form. Numerous staphylococci are also seen.

Bacteriology.-Cultures were made both from the tissue and from the pus. The prevailing forms were streptococci, but there also occurred large serum-eroding bacilli of the genus tyrothrix (Duclaux), a slender bacillus, and staphylococci.

Experiment.-Guinea-pig, 2 cc. of a bouillon culture of streptococci, incubated twenty-four hours at $37^{\circ}$, were injected into the peritoneal cavity. Eight days after the injection the guinea-pig was killed. In the abdominal cavity was found a considerable quantity of serum mixed with blood, but there was no pus. Several blood clots were found in the neighbourhood of the lungs. The spleen was slightly enlarged, and the liver was enlarged and friable. The most marked lesion occurred in the areolar tissue between the skin and the abdominal wall. It was greatly increased in volume and of a dark red colour. The lesion extended over about one third of the inferior abdominal wall round the point of injection.

Cultures from this gross lesion were made, and the micro-organism was recovered.

\section{The Parenchymatous or Hamorrhagic Type.}

CASE I.-Lesion acute. The cow in this case was killed a few hours after parturition. Both quarters of the left half of the udder were affected. They were greatly enlarged and pink in colour. The skin was loose, and a soft layer of tissue seemed to exist between it and the underlying induration; the latter consequently felt smooth. On section there was a yellow gelatinous exudate in the areolar tissue between the skin and the parenchyma, and yellow serum flowed from it. The parenchyma was of firm consistency throughout, and serum and colostrum exuded from it, but no pus. On the cut surface large 
continuous areas of the parenchyma were purplish in colour, while the remaining areas were still of the normal yellow colour. The purplish areas indicate hæmorrhage. The lesion was extremely acute.

Unfortunately, no films direct from the tissues were made.

Histology.-On microscopic examination the sections exhibit an increase in volume of the fibrous and cellular tissue, as compared with the normal. This is partly accounted for by the fact that the udder was in the colostral stage of lactation.

Colostral corpuscles are seen inside the acini in groups. Some of the acini are normal, but the striking pathological change is the frequent desquamation, partial or complete, of the secreting cells lining them. Sometimes the line of secreting cells is completely separated from its connective tissue base, but continues to maintain its character as a lining in a wavy irregular line, partly attached to the base, and partly free in the acinus. In other cases these cells are stripped away from the base, and are huddled in a mass inside the acinus.

Sections stained with fuchsin magnified 600 diameters exhibit very trequently groups of bacilli. These are seen for the most part inside the acini. In cases in which the desquamation is complete these microbes are seen mixed up with the debris. They seem able to penetrate through the base of the acinus into the interacinous connective tissue. Groups or masses of these micro-organisms are found only inside the acini. They appear to be the same size as the bacillus coli communis, their length being one-and-a-half times to twice their width, and some of them show bi-polar staining

The only other micro-organism observed is an occasional large coccus in the lymph spaces.

Bacteriology.-A bacillus of the colon group predominated practically to the exclusion of all others in all the cultures. It differs from the bacillus coli communis in that it does not coagulate milk, but on taurocholate glucose broth ${ }^{1}$ with litmus it exhibits an acid reaction with formation of gas.

Experiment.-A guinea-pig was injected intraperitoneally with $\mathrm{I}$ cc. of a bouillon culture of this bacillus, incubated twenty-four hours at $37^{\circ}$. It died in about twenty-four hours from peritonitis, the only special features being a general faint redness and congestion of the mesenteric bloodvessels, and the presence of a little fluid in the abdominal cavity. The bacillus was recovered in a pure state, not only from the abdomen but also from the heart and spleen. Cultures exactly repeated the characteristics of the injected micro-organism.

CASE I1.- This is an illustration of a more advanced case. It occurred in an aged cow. The fore and hind quarters on the left side were affected, and the induration extended throughout their volume. The skin was loose and the induration felt stringy and ridged. The quarters were much enlarged. On section a putrid odour was exhaled, and milk, blood, and serum flowed from it. The milk sinuses were sero-purulent cavities with dark grey walls near the base of the teats. The cut surface above the sinus exhibited a variegated appearance. The ground colour was grey with small abscesses of inspissated pus dotted over it. Several hæmorrhagic areas, usually oval in shape, were liver-coloured.

\footnotetext{
1 Taurocholate glucose broth with Durham's fermentation tube. See Thompson Yates

"Laboratory Reports," Vol. IV., Part I., 1901. Liverpool.
} 
Films from the grey areas and the pus showed a profusion of microbes, the predominating forms being short bacilli. Next in numbers came minute streptococci in short chains, and a few large cocci.

The short bacillus occurred in a comparatively pure state in the liver-coloured, hamorrhagic areas, and appeared to predominate in the other areas.

Histology.-The lesion is in the subacute and partially necrotic stagc. The fibrous tissue is greatly increased in volume. Leucocytes have infiltrated most of the acini and sometimes red corpuscles. Everywhere there is evidence of blood extravasation. The acini, which are still intact, are few, and their secreting cells are enlarged and oedematous. Where the short bacilli have made their attack the acini and connective tissue are quite disorganised. The necrotic areas are frequent.

Bacteriology.-The predominating micro-organism in the cultures was a bacillus which, as far as observed, could not be differentiated from the bacillus coli communis.

Experiment. - A guinea-pig was injected intraperitoneally with I cc of a bouillon culture incubated forty-eight hours at $37^{\circ}$. The guineapig died in ten hours.

The post-mortem examination disclosed a diffuse peritonitis with a little abdominal fluid. The vessels of the small bowels were markedly injected. The spleen was very friable, the pericardium was injected, and the lungs congested. The bacillus was recovered from the thorax and abdomen wherever sought for. Cultures exhibited the same features as the injected micro-organism in every way.

CASE IV.-Lesion subacute to chronic. The left forequarter is affected. It is indurated throughout, but not much enlarged. The skin is loose, and the induration feels irregular in outline, being stringy and ridged.

On section the cut surface is greyish, exhibits many small discrete abscesses, about the size of peas, with inspissated pus. These are evenly distributed over the cut surface.

Films from the pus show micro-organisms in wonderful profusion and confusing variety. Next to minute cocci in numbers comes a short bacillus, then some larger thicker bacilli and large individual cocci, and finally a few short chains of streptococci.

Histology.-About three-quarters of the section area consists of acini smaller than normal, with connective-tissue bands surrounding small groups of acini and single acini. The fibrous tissue is increased in volume and has invaded the lobules, and by contraction it has diminished the area of individual acini. The occurrence of groups of leucocytes and of isolated groups of red corpuscles indicates frequent blood extravasations. The rest of the area consists of dull necrotic areas surrounded by broad irregular bands of connective tissue. In some places these bands show many deeply-staining cells, distinct from each other but in close proximity.

Magnified 600 diameters, these necrotic areas are seen to be collections of minute bacteria, staining indistinctly and mixed with débris. These areas are minute abscesses. Outside of the fibrous tissue bands bounding these abscesses, bacteria can be seen in the tissues in small groups, deeply stained and well-defined. Multi- 
nucleated leucocytes are very numerous where these micro-organisms occur. The latter are mostly short bacilli, the length two and a half times the breadth, apparently of the colon type; but there are a few chains of streptococci.

Bacteriology.-All of the bacteria above mentioned were recovered in the cultures. The only one which was isolated and cultivated was the tyrothrix filiformis, which was studied for the first time in this mastitis.

Experiment.-Guinea-pig. A serum culture of this tyrothrix filiformis was incubated for forty-eight hours, after which liquefaction was well begun. This growth was washed with bouillon, and I cc. of the mixture was injected intraperitoneally. There was no result.

This mastitis, like the preceding one, is one of the parenchymatous type which is passing from the subacute to the chronic stage. It is a mixed infection, but the colon bacillus is predominant.

The latter organism has completely invaded the quarter in the acute stage, producing induration throughout its parenchyma. In this vitiated tissue the pyogenic bacteria have found a suitable nidus, and their growth has resulted in the widespread abscess-formation present.

CASE VI.-Lesion acute; mixed infection. In this case the two hind quarters were affected. They were enormously enlarged, and on one small area gangrenous. The skin was tense on account of the extent of swelling, but it was not adherent, except at the small gangrenous area and that immediately surrounding it. The gangrene was in the neighbourhood of the teat.

A section made between the affected quarters disclosed, in the subdermal areolar tissue of the inferior surface, a yellow gelatinous exudate in considerable quantity. There was also a considerable escape of sero-sanguineous fluid. A section of one of the quarters was accompanied by a further escape of the same fluid. The cut surface was of variegated colour, small greyish-red areas alternating with similar yellow areas, the former predominating in frequency. There was no admixture of pus in the escaping fluid, nor any sign of abscess-formation. It was an extremely acute lesion.

Films from the Tissue.- Those taken direct from the red areas exhibit a preponderance of streptococci and some short bacilli. There are also a few large bacilli. Films from the yellow areas show almost pure streptococci.

Histology.-Magnified 50 diameters. The interacinous and interlobular connective tissues are greatly increased in amount, often enormously so, and, judging from the looseness of their texture, they are engorged with serum and lymph. Lymph spaces in the connective tissue are proportionally enlarged. The lymph corpuscles are plentiful in amount and fairly normal in appearance. The blood vessels are all notably increased in lumen and engorged with blood, and in the red areas there frequently appear to be minute spaces about the size of acini filled with blood. The acini are mostly oblong or flatter than normal, as if they had given way to lateral pressure from the increased volume of the connective tissue. Their secreting cells are, in almost every instance, wholly desquamated, and are seen free in the acini in a degenerating condition.

Magnified 600 diameters, the micro-organisms which vastly pre- 
dominate are the streptococci. They are seen in the acini in great numbers among the epithelial débris and milk traces. In the connective tissue the streptococci are not frequent, but occasional large bacilli are seen. Sometimes, however, in the connective tissue, where a lymph capillary is cut, there is an enormous amount of streptococci seen in the lumen and just outside of it in one direction. The chains are very short, being seldom over three members, but may extend to twenty. This indicates that these organisms use the lymph stream as their avenue of invasion. Sometimes large single micrococci are seen along with the streptococci in the acini.

The microscopic appearances of this streptococcus are more plainly seen in films taken from the tissues than in the tissue sections. The longest chains sometimes terminate in a coccus distinctly larger than the others. Sometimes the individual members of these long chains are double. In films taken from the red-grey areas, besides the streptococcus, bacilli are present, mostly in pairs. It appears as if the latter organisms are alone concerned in the production of hæmorrhage in these red areas, seeing they are absent in films from the yellow areas.

Bacteriology.-The cultures exhibit a variety of organisms, among which the streptococcus largely predominates. Short bacilli are the next most numerous, but they were not isolated in this instance. A large serum-liquefying bacillus made a vigoroun growth in the original cultures. This micro-organism was isolated and studied, and is the same bacillus which was found later as an epiphyte in the first normal udder described, and is identical with the bacillus subtilis save in the nature of its growth on blood-serum.

Experiments.-(I) A guinea-pig was injected intraperitoneally with 2 cc. of a bouillon culture of the streptococcus, incubated for five days. No result.

(2) Another guinea-pig was injected intraperitoneally with $2 \mathrm{cc}$. of a milk culture of the streptococcus, incubated for two days. (Milk cultures were not coagulated till after four days' incubation.) The guinea-pig died in about forty-eight hours. The post-mortem examination exhibited pus free in the abdominal cavity, of a slimy semiopaque nature, with yellow flakes throughout. The streptococcus was recovered from the pus in pure culture, and from the spleen.

CASE IX.-Lesion illustrates healing and atrophy. This udder was taken from a cow with generalised tuberculosis. Most of the organs were found to be infiltrated with the disease. The owner stated that about six weeks previous to the day of slaughter the cow "took a weed," as he termed the inflammation of the udder. Two quarters, the left fore and the right hind, were apparently normal. The right fore quarter was slightly indurated throughout, but not enlarged. The left hind quarter was shrunken to nearly one-fourth of its volume, that is, presuming its normal dimensions equalled those of the other three. It was much more indurated than the right fore quarter, and its induration was evenly distributed throughout.

This shrunken quarter was selected for examination because it differed so markedly from the cases already considered. During life, when this teat was milked, the cow showed evidence of pain and tenderness, and the fluid obtained was like serum slightly mixed with blood. 
On section the colour was much yellower than that of the normal udder, and the lobules were more or less distinctly outlined. No other distinctive features were observed.

Films from this quarter exhibited no tubercle bacilli.

The cultures made remained sterile.

Histology.-Sections stained to demonstrate tubercle bacilli failed to exhibit the organism, or any of its effects upon the tissue, and other stains only exhibited a few groups of short bacilli, and large isolated cocci. The acini were smaller than normal, and often appeared compressed. The secreting cells in whole areas were entirely wanting, and where they occurred they showed great desquamation and disintegration. The connective tissue between the acini was increased in volume.

The shrinking up of the quarter must have been the result of the contraction of the interacinous and interlobular connective tissue, and the disappearance of a large proportion of the secreting cells of the acini. This contraction and atrophy of the inflamed quarter is, considering the ravages effected by the bacteria, the most desirable termination possible.

CASE X.-Chronic enlargement without marked induration. In this mastitis only one hind quarter was affected. The skin over it was everywhere loose, but the quarter was considerably enlarged. The induration was not so marked as usual, and manipulation seemed to reveal that the central mass was denser than the peripheral parts. This led to a suspicion of tubercular lesions.

On section it did not present any visible alteration from normal tissue, except that here and there occurred a thin streak of white fibrous tissue. No abscess or pus was visible.

Films direct from the udder were made with a view to discern tubercle bacilli, but none were found.

Histology. - Magnified 50 diameters. Sections show a marlied increase in the interacinous connective tissue. The acini sometimes exhibit desquamation of their secreting cells. Magnified 600 diameters. The micro-organisms are not very plentiful in the section. Small oval forms of the colon type occur in groups inside the acini and among the secreting cells, and occasional short chains of streptococci are seen in the interacinous connective tissue.

Bacteriology. - Of six blood-serum cuitures only one remained sterile. The most numerous colonies were those of streptococci, both the large and small forms, the latter greatly predominating. The next most frequent colonies were the slimy grey and white ones characteristic of the large micrococci of the normal udder.

Experiment.-Guinea-pig. 2 cc. of a bouillon culture of the large micrococcus were injected intraperitoneally. No result. So far as it goes, this experiment indicates that these epiphytic cocci are not enhanced in virulence when found in a mastitis.

Two kinds of large bacilli were found. One was of the genus tyrothrix (Duclaux), and the other resembled the bacillus subtilis.

The pathogenic bacteria in this mastitis exhibited a low degree of virulence, since so little alteration apparent to the unassisted eye had taken place during the time that must have elapsed while the white fibrous streaks were in process of formation.

CASE XI.-Lesion acute, with partial necrosis. The cow in this case 
had died of septicæmia. There was apparently acute inflammation of the left hind quarter of the udder. The teat of this quarter had been partially removed by injury. The skin of the teat and that covering the neighbourhood of its base was thickened, but movable. A yellow necrotic area was visible on the teat, and the exposed and injured tissue was probably the avenue of the infection from which the animal perished. The quarter was markedly and evenly tumefied.

On section there was no visible pus, but much fluid escaped. The tissue had a greyish appearance, with yellow necrotic patches here and there about the base of the teat.

Films from the tissue.-Those made from the necrotic areas show a marvellous profusion of organisms. The most numerous are staphylococci; next, large and small diplococci, streptococci in short chains, and short bacilli with only occasional larger bacilli, and single large cocci. The short bacillus predominates in films from other parts of the lesion, and is of two kinds, one resembling that of Cases I. and II., another always exhibiting only bi-polar staining.

Histology.-Sections exhibit great engorgement of the lymphatic vessels and lymph spaces, and of the bloodvessels. The interlobular connective tissue is increased in volume, but this is owing to engorgement by lymph, for the nuclei of the connective-tissue cells have not increased with the volume of the tissue. The acini appear rather smaller than normal, as if they were being densely packed together. Many are otherwise fairly normal in appearance, but most of them are injured by the action of the microbes. Desquamation is frequent, and so is partial disarrangement of the secreting cells, but seldom are they disorganised. These cells are cedematous, and their enlarged condition gives the picture a crowded appearance.

The tissue section is rich in organisms. The most frequent are short bacilli, which occur loosely arranged in groups, especially among broken up acini. There are some small masses of staphylococci, and occasional short chains of streptococci.

Bacteriology.-The above micro-organisms were all recovered in the cultures. The short bacillus was found to be one of the colon group.

CASE XII.-Lesion subacute to chronic, with advancing necrosis. No history of this case was obtained. One quarter only was affected, and it was greatly enlarged and evenly indurated throughout. The skin was loose and the induration felt ridgy. On section the subdermal areolar tissue appeared normal. The cut surface was lobulated, and the colour was greyish, this effect being produced by minute areas of greenish-yellow inspissated pus upon a light brown ground. The induration was not so intense as that of tubercle, and the affection appeared to be subacute inclining to chronicity.

Films from the pus exhibited great profusion and variety of microorganisms, bacilli being almost as numerous as cocci. The bacilli were small; some deeply, and some lightly, stained. The lightly stained bipolar bacilli were the most numerous, and occurred now for the first time in this series (for description, vide infra). The cocci were small, single, and in groups. Some short chains of streptococci occurred, and a ferv large cocci.

Films from the tissue were not very much inferior to those from the pus in number of organisms, but the latter were more clearly defined. 
On account of the lobulation seen on section of the quarter resembling tubercle, films from the udder and one from the tissue section were stained by the Ziehl-Neelsen method, but did not exhibit tubercle bacilli.

Histology.-The interacinous and interlobular connective tissue was markedly increased. The acini were compressed, and all of them showed partial or complete desquamation of secreting cells. Small abscess areas were very common. These tissues had a necrotic appearance, and micro-organisms swarmed in numbers which I have never seen equalled. Among them the unusual form above-mentioned was very common.

Bacteriology.-The growths on the original cultures were, as expected, of a very mixed character indeed. Films from them exhibited apparently all of the before-mentioned forms.

Microscopical appearance of the predominating bacillus.-It is a thick organism, its length being two or three times its width. It is usually pointed at both ends, in which case the staining is at both ends, but it is often rounded at one end, and stained at the pointed end. By fuchsin it is practically unstained except at one or both extremities. This feature is constant, and complete staining is only obtained by treatment with hot stain. In decolourising with dilute sulphuric acid the stain is completely given up, except a faint indication of colouring at the extremities. The best staining effect was obtained by first treating the film with absolute alcohol and then with cold fuchsin. By this method stained areas at the extremities amounted to about two-thirds of the organism, leaving one-third in the centre unstained. A large proportion of individuals are distinctly curved when in chains, which is very frequent in bouillon cultures. They are not exactly joined end to end, but the succeeding individual is attached to the convex surface near the point of its predecessor, the point itself being free. They are extremely motile, most of them darting with a fishlike motion, while a few show rotatory motion. Spores were not observed. In staining by Gram's method only the ends retain the stain, and that very faintly indeed. Curved forms are seen mostly in liquid media, not in the tissue.

Cultures.-Agar, twenty-four hours. Circular colonies raised above the surface, rounded on the top, but more flat than dome-like. Growth less vigorous than in bouillon.

Bouillon, twenty-four hours. Distinct turbidity, no collarette, and very slight deposit. The individual organism is larger than in agar, chains as already described being very common. Filaments are also common. They are distinctly wavy, resembling a spirillum, and the length from the summit to the depth of the wave is exactly that of the ordinary microbe. The turning point of the wave is more pointed than rounded. Occasionally a small, fully-formed bacillus is seen in the middle of the filament. The filaments mounted in bouillon exhibit immense activity.

Milk. No coagulation, and only slightly thickened in old cultures.

Taurocholate glucose broth, with litmus, is turned red in two days, but no gas is formed. Reaction acid.

Gelatine stab. The medium is liquefied. In two or three days there is a sack-like projection down the needle track from the surface. The liquid gelatine has a whitish-green appearance. 
Experiment.-A guinea-pig had $2 \mathrm{cc}$ : of a bouillon culture, twentyfour hours incubated, injected intraperitoneally. In eighteen hours it was found dead. Little change was observed on post-mortem examination, but a large amount of sero-sanguineous fluid was found in the peritoneal cavity. Films of this fluid exhibited the micro-organism injected, but rather sparsely distributed. They were plumper in form than any I had yet seen, and resembled a grain of barley in shape.

Cultures of the organism isolated from this fluid gave the same results as those already described.

This micro-organism exhibits features which relate it to the vibrios, notably the motile chains of curved forms, and the spirilliform filaments seen in bouillon.

CASE XIII.-Lesion acute. The cow from which this mastitis was taken had not yet shed its placenta, and was killed the day after parturition. The whole udder was enlarged and tense, which is often, in such a case, the normal condition. But one hind quarter was very specially so, and the skin of that quarter seemed thickened, but was easily movable.

On section of this quarter a great quantity of sero-sanguineous fluid flowed out. The cut surface exhibited a number of red areas on a normal coloured ground. The lesion was very acute. There were no purplish nor grey areas, nor was there any pus.

Films from the tissue serum. - There was not, relatively speaking, a great number of micro-organisms observed, and these consisted mainly of micrococci of three varieties. The vast majority of them were the large cocci common to the normal udder. They seemed to be in active proliferation, showing very frequent transverse segmentation. They occurred in groups and sometimes in masses, often they took the form of chains of three and two, and frequently the form of tetrads. Occasionally groups of smaller staphylococci were seen, but only one or two chains of streptococci. A few isolated short bacilli were noted, and one or two large bacilli. The large coccus was the predominating organism.

Histology.-The connective tissue between the lobules of acini was increased, but the tissue appeared loosely arranged, leaving frequent spaces in it. The interacinous connective tissue showed a wonderful wealth of leucocytes and connective-tissue cells, but this may bc normal during the colostral period, though part of the excess was no doubt due to the irritation of the pathogenic microbes. The acini were to a large extent quite uninjured by microbes. The contents of the acini appeared to have greater consistency than normal milk, and in most cases contained round deeply-stained colostral corpuscles. There appeared to be great differences between the normal acini. In some the interacinous area was plentifully dotted over with the colostral corpuscles, and the secreting cells seemed at rest.

In others the secretion of colostrum was manifestly active. In these latter the secreting cells were about three times the normal length, projecting towards the interior of the acinus. They had an irregular palisade appearance. The large nucleus proper of each cell was generally situated near the base of the acinus, while at its distal extremity it was ragged and irregular from the detachment of colostral corpuscles. These on leaving the parent cells were enveloped by a narrow zone of protoplasm. The length of the secreting cells in the 
active acini was such that the central area was diminished at least by half.

The micro-organisms seen in the tissues were not so numerous as might have been expected. Short bacilli, loosely grouped, were seen occasionally inside the acini, and were the cause of partial desquamation of the secreting cells, where they occurred. Cocci were not seen except of the large variety in isolated instances. The same may be said of large bacilli which were mostly club-shaped.

Bacteriology.-In all the cultures short bacilli occurred and quite predominated in number of colonies. Next in number of colonies came the large cocci of the normal udder, and, lastly, small discrete colonies of streptococci in short chains of very small numbers. The predominating short bacillus was not studied exhaustively, but it offered no special features which are not common to the colon group so far as observed.

CASE XIV.-Lesion acute. In this mastitis the left fore and hind quarters were attached. They were greatly enlarged, the induration was evenly distributed throughout, and the skin, though not thickened nor attached, was tense owing to the swelling. The hind quarter was selected for examination.

On section not much fluid escaped. In the subdermal areolar tissue a considerable amount of yellow gelatinous exudate was found. This was situated over the lower third of the quarter, especially in the neighbourhood of the teat. The cut surface exhibited areas of yellow and red, which were very sharply defined. The red or hæmorrhagic areas were most frequent towards the teat, but extended throughout the quarter. Sometimes these hæmorrhagic areas were large and continuous, and sometimes they were like red blotches on a yellow ground. Both red and yellow areas were indurated to the same degree. The milk reservoir was filled with a pus-like fluid. No pus was visible in the solid tissue. The lesion was a very acute one, and, after the cut quarter had lain for several hours, a great deal of serosanguineous fluid was found to have exuded.

Films direct from the tissues: hamorrhagic arcas.-The vast majority of micro-organisms are small short bacilli. One or two small masses of small cocci occur.

Yellow area.-Still the short bacilli are in the majority, but not in such great numbers as in the red area. Streptococci are common, in chains of from two to about twelve members. The large cocci occur occasionally. The main difference between the red and yellow areas is that the red contain the short bacilli in enormously greater numbers, and in seemingly greater vigour, judging from the depth of the staining.

Histology: tissue sections from red area. The impression given is that the lesion is very acute. Connective tissue cells have greatly increased in number, and in parts lymph spaces are very common, indicating engorgement. The cut bloodvessels are enlarged in lumen, and in one or two areas of the section there is extravasation of blood. The acini, as a rule, show partial and often complete desquamation of secreting cells. Many areas are simply confused masses of connective tissue and secreting cells.

Magnified 600 diameters. The short bacilli are very numerous in the broken up acini. Their method of attack is seen in those not yet 
entirely broken up. They occur in streak-like multitudes on one side of the acinus, between the layer of secreting cells and the connective-tissue base. This explains why so large a proportion of acini are completely desquamated.

Bacteriology.-In all the cultures the predominating microbe was the short bacillus, which was found to belong to the colon group. The other micro-organisms recovered were streptococci, large staphylococci, and a sporing bacillus. The only distinctive feature which the colon bacillus offers is the appearance of involution forms in subcultures. The bacilli become vacuolated at one or both ends.

Experiments.-(I) Guinea-pig, $2 \mathrm{cc}$. of a bouillon culture of the colon bacillus, after twenty-four hours' incubation at $37^{\circ}$, was injected intraperitoneally. No result.

(2) Rabbit. It had the same dose of the same culture intraperitoneally. No result.

(3) Rat (white). It was injected intraperitoneally with $5 \mathrm{cc}$. of the same culture. It died in about thirty-six hours. Post-mortem examination exhibited a small amount of fluid in the abdominal cavity. The border of the liver was livid. No morbid changes were observed in the thorax.

The bacillus was recovered from the abdominal fluid, the liver, and various parts of the thorax.

\section{GENERAL CONSIDERATIONS.}

In attempting to generalise upon the examination of fourteen cases of mastitis, it is fully admitted that types of the disease may occur which have not been observed in this series.

So far as our examinations go, they indicate that all udders of cows, both normal and diseased, have a bacterial flora. In the normal udder these bacteria are non-pathogenic. They appear to exist as epiphytes in the milk ducts. But, when the vitality of the udder is greatly lowered, such of them as are capable of pathogenic action can induce mastitis.

The variety of micro-organisms found in normal and diseased udders indicates that the bacteria found there depend wholly on the accident of their advent from the external environment, and upon their power to maintain their existence either as epiphytic or pathogenic forms. The occurrence of the vibrio in Mastitis XII. leads to the belief that there is probably an immense variety of pathogenic bacteria which are capablc of producing mastitis, and that new types of the disease will be constantly emerging.

Classification.- The cases of mastitis considered in this series have been described under three groups: tubercular, purulent or streptococcal, and the parenchymatous or hæmorrhagic groups.

Tubercular mastitis. - Mastitis due to the invasion of the tubercle bacillus is specific and distinctive enough to need no further notice than reference to the cases described, numbers III. and V.

The purulent type.-This is exemplified in cases VII. and VIII. These are characterised by great thickening of the skin and subdermal areolar tissue, and by large pus sinuses, frequently connected with each other, and having very thick connective tissue walls with an internal lining of false necrotic membrane, blue-black or brown in colour. 
This condition begins in the lower third of the quarter, and has a slow upward invasion. The upper stratum of parenchyma, which is uninvaded by purulent processes, is very soft and increased in volume through passive œdema. The predominating micro-organisms, which appear to be the cause of these changes, are streptococci of a low degree of virulence.

The parenchymatous or hamorrhagic type.-Cases of this type are acute and subacute, the latter sometimes terminating in necrosis and discrete abscesses. This type is exemplified in cases I., II., IV., VI., IX., X., XI., XII., XIII., and XIV. The distinctive features of this type are the rapid and complete invasion of the whole quarter or quarters effected, diffuse or local hæmorrhages throughout the affected area, enlargement and induration due to infiltration of the interacinous and interlobular connective tissue by lymph, and in subacute and chronic stages this tissue is increased. In all the cases I have described under this type diffuse and local hæmorrhages were a constant feature. The micro-organisms which predominate in these hæmorrhagic areas are bacilli of the colon type. They differ from each other in some of their cultural features, and in their pathogenic effect upon laboratory animals. Esherich, in his investigations into the bacteria found in the intestines and faces of healthy children, found a group of colon bacilli presenting similar variations in their morphological and biological features. Two American investigators, Booker and Jeffries, ${ }^{1}$ in their study of summer diarrhoea in milk fed infants, obtained similar results with regard to bacilli of the colon type. They found several varieties of bacilli closely resembling Esherich's bacillus coli communis, some of which were rapidly fatal to laboratory animals, and some of which were not.

In Case VI. the predominating micro-organism is undoubtedly a streptococcus. The reason of its inclusion in the parenchymatous group is that the streptococcus, which was of unusual virulence, had, along with the colon bacillus, completely and rapidly invaded the two hind quarters, producing induration throughout and local hæmorrhages. The latter are undoubtedly due to the action of the bacillus of the colon group.

In sub-acute cases of this type small discrete abscesses with inspissated pus are invariably present, and sometimes one or two may reach the size of walnuts. Still the type is sharply distinguishable from that designated purulent by the induration existing throughout the entire quarter. Sometimes the necrotic changes are so widespread that the hæmorrhagic areas are obscured.

Mastitis in cows has an important bearing in relation to the milk supply, but it is difficult to obtain even an approximate estimate of the proportion of diseased udders which may effect it.

Swithinbank and Newman, ${ }^{2}$ when writing on this subject, quote as the opinion of Professor M'Fadyean, in agreement with many other authorities, "that about 2 per cent. of the cows in the milking herds in this country are thus affected" (i.e., have tuberculous udders). The question of tubercular contamination of milk from this source has already been so often and carefully studied that I propose to confine

\footnotetext{
1 "Transactions of the International Medical Congress," Ninth Session, Vol. III.; also "Archives of Pediatrics" Vol. VII.

2 "Bacteriology of MTilk," 1903, p. 215.
} 
myself to the risks of milk infection from mastitis of other than tubercular origin.

There is no doubt that the percentage of cows suffering from mastitis of other than tubercular origin is very much higher than 2 per cent. The same authors give a table of the results of periodic veterinary inspections of the milch cows stabled in the metropolis which were carried out by the London County Council from 1899 to 1903. From this table it appears that, omitting actual and suspected cases of tubercular mastitis, the percentage of which was very low, the percentage of diseased udders varied from 13.2 to 4.8 . The list of lesions enumerated are: "subjects of acute mastitis, affected with chronic induration of the udder, atrophy of one or more quarters, injuries, abscesses, simple eruptions, strictures and obliterations of milk ducts, and hypertrophied udders without induration." It is added that "these figures included cases of recently recovered udder disease, and a few cows removed by owners to avoid infection."

Partial restoration is the most that can be hoped for in a quarter or quarters which have been the seat of inflammation. The milking value of such a quarter is invariably reduced on account of the ravages of the causal micro-organism in the parenchyma. In such cases as have yielded to treatment to an extent which appears to justify the use of the milk for human food there may be grave risk to the consumer. Such udders are a probable source of the colon bacilli and streptococci so often found in milk, and incidentally of pus cells. These microorganisms I mention because they are the commonest pathogenic bacteria found in parenchymatous and hæmorrhagic mastitis, but the infection is mostly a very mixed one. These bacteria and some of the tissue débris are largely eliminated through the milk, and it is this period of elimination which constitutes the danger, for of necessity it must be a very indefinite period.

With a view to connect the pathogenic effect of these bacteria on the consumers of milk, the following is quoted from Swithinbank and Newman, pp. 364, 365: "That epidemic diarrhœa is caused by the bacillus coli either alone or in conjunction with other organisms, has been held by a number of authorities. Cumston, who investigated thirteen cases of the disease, concluded that bacillus coli associated with streptococcus pyogenes was the chief pathogenic agent concerned, and he claims that the virulence of bacillus coli is exalted by the association. Lesage also formed the opinion that the disease was due to bacillus coli, and investigated the agglutinative properties of the serum of children suffering from epidemic diarrhoea on bacillus coli isolated from the intestine. He obtained a positive result in forty out of fifty cases, and the serum of each of these forty cases also agglutinated samples of bacillus coli from thirty-nine other children seized with the same disease. Some of the most recent work on the relationship existing between bacillus coli and epidemic diarrhœa has been done by Delépine, who examined milk in the outbreak of epidemic diarrhoea which occurred in Manchester in 1894 (vide infra), and has also examined a large number of town and country milks. His conclusion is that :-

"Epidemic diarrhcea of the common type occurring in this country is apparently, in the great majority of instances, the result of infection of food by bacilli belonging to the colon group of bacilli, and which 
are present at times in fæcal matter. It appears that this infection of food does not generally lead to serious consequences, unless the infection is massive from the first, or the food is kept for a sufficient length of time, and under conditions of temperature favouring the multiplication of these bacilli.

"Milk, which is the most common cause of epidemic diarrhoea in infants, is usually infected at the farm or (through vessels) in transit. Of the bacilli of the colon group which are capable of rendering the milk infectious, those which do not produce a large amount of acid, and do not coagulate milk, are the most virulent, and are probably the essential cause of epidemic diarrhoea!

"Fliigge and Suibert believe that cows' milk contains at certain seasons arobic spore-bearing bacilli of the subtilis type, which have the power of decomposing and peptonising milk, producing metabolic products, which when swallowed by animals cause diarrhoea, etc., and which may therefore produce diarrhoea in infants."

In preparing this work I gratefully acknowledge the courtesy of the Council of the Royal College of Physicians, Edinburgh, and the assistance and advice of Dr Noel Paton, Director of Research, of Dr W. T. Ritchie, and of the Laboratory assistants. I have also to thank Dr Paton for performing five experiments for me.

\title{
SPIRILLOSIS OF CATTLE.
}

\author{
By A. Theiler, Bacteriologist to the Transvaal Government, \\ Pretoria.
}

\section{DEFINITION,}

Nocard and Leclainche, in their book Les maladies microbiennes, introduced the name "spirillosis" for a disease in geese, due to the presence of a spirillum in the blood of the sick birds (Spirochrte anserina). This spirillum was discovered by Sakharoff in the TransCaucus, and was the first pathogenic microbe of the genus spirillum found in animals. A disease in men also due to a spirillum (Spirochæte Obermeyeri) has been known for many years under the name of " recurrent fever."

In I902 I noticed a certain spirillum in cattle, but at that time I did not attach much importance to this microbe. Since then I met with the same parasite in several instances, and always in company with definite pathological features.

At the beginning of last year Laveran, to whom I sent several preparations from sick animals, made a communication regarding the subject to the Academie des Sciences under the name "Sur la Spirillose des Bovides," and called the micro-organism "Spirillum Theileri." In September of last year Drs Marchoux and Salimbene published an article on "La spirillose des poules" in the Annals of the Pasteur Institute. This disease was found in fowls in and around the town of Rio de Janeiro, and was of a very deadly character. This is therefore the third disease observed in animals known under the name of spirillosis. 